\title{
Challenges and opportunities of bioenergy with CCS (BECCS) technologies
}

\author{
Lin Ma \\ Professor of Fluid Dynamics \\ Department of Mechanical Engineering \\ The University of Sheffield, United Kingdom
}

\begin{abstract}
With the continuous increase in the level of $\mathrm{CO} 2$ in the atmosphere, it is generally agreed that developing negative emissions technologies are indispensable in order to meet the carbon budget that is required to keep a global temperature rise well below 2 degrees. Bioenergy with carbon capture and storage (BECCS) is seen as one of the most viable and cost effective such negative emissions technologies. This talk will present some of the challenges and opportunities of the technology development with a focus on combustion for power and heat. Recent work on combustion of biomass and carbon capture technologies will be discussed and directions for future research will be suggested.
\end{abstract}

